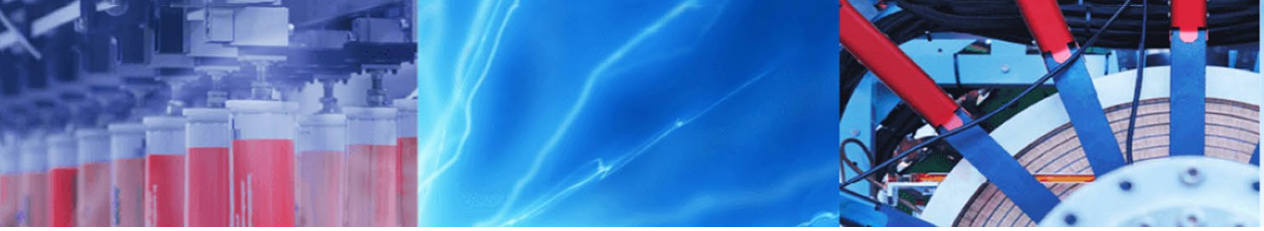

Research Article

\title{
Mechanical and durability properties of bagasse ash-blended high-performance concrete
}

\author{
S. Praveenkumar ${ }^{1}\left[\right.$. G. Sankarasubramanian ${ }^{1}$
}

Received: 11 February 2019 / Accepted: 16 November 2019 / Published online: 25 November 2019

(c) Springer Nature Switzerland AG 2019

\begin{abstract}
The use of supplementary cementitious materials has become an integral part of high-strength and high-performance concrete mix design, which may be natural by-products or industrial wastes. Some of the frequently used supplementary cementitious materials are fly ash, silica fume, ground granulated blast furnace slag, rice hush ash and bagasse ash (BA). BA (sugarcane industry waste product) is considered to be an active pozzolan because of its large surface area with significant amount of amorphous $\mathrm{SiO}_{2}$. The mix design for high-performance concrete is done as per the method proposed by P. C. Aitcin. This method is simple and follows the same approach as ACl 211-1 standard practice for selecting proportion of normal, heavy and mass concreting. Ordinary Portland cement was replaced at different levels of $0 \%, 5 \%, 10 \%$, $15 \%$ and $20 \%$ by BA. This investigation presents results on the strength and durability properties of high-performance concrete with and without BA, which includes cube compressive strength, splitting tensile strength, flexural strength, saturated water absorption, sorptivity, porosity, impact test and alkalinity measurement. The test results indicate that the incorporation of BA up to $10 \%$ provides improved properties of hardened concrete.
\end{abstract}

Keywords Bagasse ash $\cdot$ High-performance concrete $\cdot$ Mechanical properties · Durability properties

\section{Introduction}

Major construction projects today around the world use ordinary Portland cement as a binder for manufacturing of mortar and concrete [1]. Production of cement emits carbon dioxide worldwide, which causes environmental issues such as dust pollution and thinning of ozone layer, which leads to global warming [2]. Utilization of supplementary cementitious materials as a partial replacement of cement mortar and concrete is the most effective way of reducing the environmental impact, which also minimizes energy, cost and waste emission [3,4]. The wastes from various industries such as silica fume, fly ash and blast furnace slag were used as mineral admixtures. Bagasse ash, rice husk ash and wheat straw ash were also being used as pozzolanic materials in various forms $[5,6]$. Mineral admixtures as partial replacements of cement improve the mechanical and durability properties of concrete [7].

In India, sugarcane production was about 300 million tons per year [8] and plenty of bagasse is available in sugar industry. Bagasse is partly used as fuel in sugar industry and the remaining was dumped in ground. Silica content present in the pozzolan reacts with the free lime during hydration and forms calcium silicate hydrate (CSH) [9]. During hydration process, formation of $\mathrm{C}-\mathrm{S}-\mathrm{H}$ gel improves properties of blended (cement and supplementary cementitious material) hardened concrete. However, hydration time is inversely proportional to the porosity, which also increases pore structure and permeability of mortar and concrete. The waste from agro-industry was burnt in incinerating temperature of below $700{ }^{\circ} \mathrm{C}$ for $1 \mathrm{~h}$ which converts the silica content of the ash into amorphous phase

S. Praveenkumar, spk.civil@psgtech.ac.in; G. Sankarasubramanian, gsa.civil@psgtech.ac.in | ${ }^{1}$ Department of Civil Engineering, PSG College of Technology, Coimbatore, Tamil Nadu, India. 
[10]. In order to achieve the required size, ash was grinded in laboratory ball milling. The grinded ash mixed with ordinary Portland cement produces blended cement. The characteristics of agricultural industry waste ash purely depend on the following process such as burning, maintaining constant temperature, drying and grinding.

The objective of the present study is to assess the performance of bagasse ash as supplementary cementitious material in mechanical and durability properties of highperformance concrete, as well as to make out the optimal level of replacement.

\section{Materials}

\subsection{Cement and bagasse ash}

OPC 53 grade was used for making high-performance concrete specimens. The bagasse ash used in the test was obtained from Gobichettipalayam, TN, India. Bagasse ash varied up to $20 \%$ by weight of cement. The used cement and bagasse ash have specific gravity of 3.15 and 2.18. Initial and final setting time of ordinary Portland cement is found to be $80 \mathrm{~min}$ and $150 \mathrm{~min}$ with $29.5 \%$ standard consistency. The chemical composition of the cement and the bagasse ash is shown in Table 1.

\subsection{Aggregate}

Coarse aggregate in surface dry condition of size confirming to $20 \mathrm{~mm}$ was used. River sand was used as fine aggregate in saturated surface dry condition. Coarse aggregate and fine aggregate specific gravity is found to be 2.85 and 2.66. Water absorption of coarse aggregate and fine aggregate was $0.85 \%$ and $3.09 \%$, respectively. All the aggregates were conforming to IS 383: 2016 [11] specifications.

\subsection{Super plasticizers}

The properties of super plasticizer were given as polycarboxlic ether-based super plasticizer, colour-light brown, and specific gravity $-1.08 \pm 0.01$ at $25^{\circ} \mathrm{C}, \mathrm{pH} \geq 6$. The dosage of super plasticizer is adopted is $10 \mathrm{~L} / \mathrm{m}^{3}$ of concrete. It was primarily developed for application in high-performance concrete for reducing water content.

\section{Experimental work}

\subsection{Mix proportion and casting of HPC specimens}

M60 grade mix design was done as per the method proposed by Aitcin [12], a simple approach that follows ACI 211-1 standard practice. The mix proportions for all the specimens are given in Table 2. Cement content is $510 \mathrm{~kg} /$ $\mathrm{m}^{3}$ for the control specimen and $5 \%, 10 \%, 15 \%$ and $20 \%$ of cement are replaced by bagasse ash for the remaining mixes. The weight of fine aggregate and coarse aggregate is $809 \mathrm{~kg} / \mathrm{m}^{3}$ and $1125 \mathrm{~kg} / \mathrm{m}^{3}$, respectively. The water content of the mix and W/B ratio is $130 \mathrm{~kg} / \mathrm{m}^{3}$ and 0.28 . The dosage of the super plasticizer was adopted as $10 \mathrm{~L} / \mathrm{m}^{3}$ of concrete. The mixes were designated as HPC-BAO for control specimen and HPC-BA1-HPC-BA4 for bagasse ashblended high-performance concrete.

Ordinary Portland cement was replaced with bagasse ash of proportions 5, 10, 15, 20\% by weight of cement. Five different concrete mixtures including control mixtures were prepared with a water binder ratio of 0.28 . Concrete was mixed for about $5 \mathrm{~min}$ in laboratory drum mixer. The details of the number of concrete specimens cast for the present study are as follows: cube specimens of size $150 \mathrm{~mm}$ of 30 Nos., cylindrical specimens of size $150 \mathrm{~mm}$

Table 1 Chemical composition of cement and bagasse ash (\%)

\begin{tabular}{lllllllll}
\hline Parameter & $\mathrm{SiO}_{2}$ & $\mathrm{Al}_{2} \mathrm{O}_{3}$ & $\mathrm{Fe}_{2} \mathrm{O}_{3}$ & $\mathrm{MgO}$ & $\mathrm{Na}_{2} \mathrm{O}$ & $\mathrm{K}_{2} \mathrm{O}$ & $\mathrm{CaO}$ & LOI \\
\hline Cement & 11.99 & 2.64 & 4.03 & 0.85 & 0.54 & 1.52 & 70.93 & 0.8 \\
Bagasse ash & 55.49 & 9.92 & 8.29 & 7.96 & 0.93 & 8.34 & 8.74 & 5.4 \\
\hline
\end{tabular}

Table 2 Mix proportion

\begin{tabular}{lllllllll}
\hline Mix no. & $\begin{array}{l}\text { Bagasse } \\
\text { ash (\%) }\end{array}$ & $\begin{array}{l}\text { Water } \\
\text { binder ratio }\end{array}$ & Cement $\left(\mathrm{kg} / \mathrm{m}^{3}\right)$ & $\begin{array}{l}\text { Bagasse ash } \\
\left(\mathrm{kg} / \mathrm{m}^{3}\right)\end{array}$ & $\begin{array}{l}\text { Fine aggre- } \\
\text { gate }\left(\mathrm{kg} / \mathrm{m}^{3}\right)\end{array}$ & $\begin{array}{l}\text { Coarse aggre- } \\
\text { gate }\left(\mathrm{kg} / \mathrm{m}^{3}\right)\end{array}$ & $\begin{array}{l}\text { Super plasti- } \\
\text { cizer }(\mathrm{L})\end{array}$ \\
\hline HPC-BA0 & 0 & 0.28 & 510.00 & 00.00 & 809 & 1125 & 10 & 130 \\
HPC-BA1 & 5 & 0.28 & 485.85 & 24.15 & 809 & 1125 & 10 & 130 \\
HPC-BA2 & 10 & 0.28 & 461.70 & 48.30 & 809 & 1125 & 10 & 130 \\
HPC-BA3 & 15 & 0.28 & 437.55 & 72.45 & 809 & 1125 & 10 \\
HPC-BA4 & 20 & 0.28 & 413.4 & 96.60 & 809 & 1125 & 10 & 130 \\
\hline
\end{tabular}


diameter and $300 \mathrm{~mm}$ height of 30 Nos., prism specimens of size $100 \mathrm{~mm} \times 100 \mathrm{~mm} \times 500 \mathrm{~mm}$ of 30 Nos., cube specimens of size of $100 \mathrm{~mm}$ of 63 Nos., and disc specimens of size of $152 \mathrm{~mm}$ diameter and $62.5 \mathrm{~mm}$ thickness of 21 Nos. After $24 \mathrm{~h}$ of casting, the test specimens were demoulded and immersed in water for curing, till the age of test.

\subsection{Mechanical properties}

The cube compressive strength was calculated as per IS 518-2004 [13] for bagasse ash-blended high-performance concrete. Splitting tensile strength was carried out on bagasse ash-blended high-performance concrete cylinders as per IS 5816-2004 [14]. Prism specimens were cast to determine the flexural strength of bagasse ash-blended high-performance concrete. The test was carried out at the age of 7 and 28 days curing.

\subsection{Durability properties}

Saturated water absorption (SWA) tests were carried out on bagasse ash-blended high-performance concrete cube specimens as per ASTM C642 [15] at the age of 7 and 28 days curing. SWA of bagasse ash-blended HPC is used to assess of the pore volume or porosity in hardened concrete which is occupied by water in saturated condition. It represents, in saturated bagasse ash-blended HPC specimens, the amount of water which can be separated on drying. The porosity obtained from absorption tests is designated as effective porosity. The formula used to calculate the effective porosity: (volume of voids $\left(W_{\mathrm{s}}-W_{\mathrm{d}}\right) /$ bulk volume of specimen $\left.\left(W_{\mathrm{s}}-W_{\text {sub }}\right)\right) \times 100$, where $W_{\mathrm{s}}$ is weight of specimen at fully saturated condition, $W_{d}$ is weight of oven-dried specimen and $W_{\text {sub }}$ is submerged weight of specimen in water [16]. Sorptivity measures the rate of infiltration of water into pores available in concrete. The sorptivity values of bagasse ash-blended high-performance concrete specimens after 28 and 90 days were calculated using the formula $I=S \times T^{0.5}$, where $I$ is absorption per unit area $(\mathrm{mm}), S$ is sorptivity $\left(\mathrm{mm} / \mathrm{h}^{0.5}\right)$ and $T$ is the time elapsed [17]. The impact strength tests were carried out on bagasse ash-blended high-performance concrete specimens at the age of 28 days curing using drop weight testing device as per ACl Committee 544. 2R-89. By using hammer, tested bagasse ash-blended high-performance concrete cube specimens were broken into small pieces. Further, the small pieces were powered using laboratory ball milling and pulverizer. For all the mixes, processed powder sample was tested for alkalinity.

\section{Results and discussion}

\subsection{Compressive strength}

Compressive strength results of HPC mixes with bagasse ash (HPC-BA) at the age of 7 , and 28 days curing is given in Table 3. The compressive strength of HPC mixes containing bagasse ash decreases at 7 days curing compared to that of conventional concrete. HPC mixes with bagasse ash HPC-BA1 and HPC-BA2 show improvement in the compressive strength at 28 days curing, which was up to $6 \%$ compared to the mix without bagasse ash (HPCBA0). HPC-BA3 and HPC-BA4 specimens show decrease in the compressive strength of $10.5 \%$, respectively. Thus from the results, it has been observed that the maximum compressive strengths were obtained for mixes HPC-BA2 (10\%). Increase in the compressive strength may be due to reaction of bagasse ash with calcium hydroxide and formation of CSH gel [18]. The calcium silicate hydrate is the component which gains strength due to binding effect. Up to $10 \%$ replacement of cement with bagasse ash shows increased compressive strength. Addition of bagasse ash beyond $10 \%$ has no significant reaction with calcium hydroxide. Excess bagasse ash does not react or act as binder in HPC; hence, it reduces strength at 28 days curing. The variations of compressive strength of HPC mixes

Table 3 Mechanical properties of bagasse ash-blended HPC

\begin{tabular}{|c|c|c|c|c|c|c|c|c|c|c|c|c|}
\hline \multirow[t]{3}{*}{ Mix no. } & \multirow{2}{*}{\multicolumn{2}{|c|}{$\mathrm{CS}\left(\mathrm{N} / \mathrm{mm}^{2}\right)$}} & \multirow{2}{*}{\multicolumn{2}{|c|}{$\mathrm{SPT}\left(\mathrm{N} / \mathrm{mm}^{2}\right)$}} & \multirow{2}{*}{\multicolumn{2}{|c|}{$\mathrm{FS}\left(\mathrm{N} / \mathrm{mm}^{2}\right)$}} & \multicolumn{6}{|c|}{$\%$ Increase in strength } \\
\hline & & & & & & & \multicolumn{2}{|l|}{ CS } & \multicolumn{2}{|l|}{ SPT } & \multicolumn{2}{|l|}{ FS } \\
\hline & 7 days & 28 days & 7 days & 28 days & 7 days & 28 days & 7 days & 28 days & 7 days & 28 days & 7 days & 28 days \\
\hline HPC-BAO & 48.60 & 65.20 & 4.32 & 4.41 & 7.65 & 8.12 & - & - & - & - & - & - \\
\hline HPC-BA1 & 43.50 & 67.40 & 4.62 & 4.98 & 7.82 & 8.29 & 10.49 & 3.37 & 6.94 & 12.92 & 2.22 & 2.09 \\
\hline HPC-BA2 & 38.40 & 68.50 & 5.14 & 5.52 & 8.12 & 8.37 & 20.98 & 5.06 & 18.98 & 25.17 & 6.14 & 3.07 \\
\hline HPC-BA3 & 34.85 & 59.30 & 4.26 & 4.32 & 7.35 & 7.52 & 28.29 & 9.04 & 1.38 & 2.04 & 3.92 & 7.38 \\
\hline HPC-BA4 & 29.00 & 58.35 & 3.35 & 3.76 & 7.19 & 7.30 & 40.32 & 10.5 & 22.4 & 14.73 & 6.01 & 10.09 \\
\hline
\end{tabular}

CS compressive strength, SPT splitting tensile strength, FS flexural strength 
containing $5-20 \%$ of replacement of cement by bagasse ash at different 7 and 28 days are shown in Fig. 1.

\subsection{Splitting tensile strength}

Splitting tensile strength values of bagasse ash-blended high-performance (HPC-BA) at different ages are given in Table 3. The variation of splitting tensile strength and the influence of bagasse ash are shown in Fig. 2. It can be observed from the results that up to $10 \%$ (HPC-BA2 and HPC-BA3) of bagasse ash, the splitting tensile strength increases [18]. The percentage increase in splitting tensile strength at the age of 7 and 28 days is 18.98 and 25.17, compared to the conventional concrete.

\subsection{Flexural strength}

Flexural strength results of bagasse ash-blended highperformance (HPC-BA) at different ages are shown in Table 3. High-performance concrete without bagasse ash (HPC-BA0) attains a flexural strength of $7.65 \mathrm{~N} / \mathrm{mm}^{2}$, whereas flexural strength increases up to $6.14 \%$ for the specimens of HPC-BA1 and HPC-BA2 compared to HPC mix without bagasse ash. Specimens HPC-BA3 and HPCBA4 attains lower flexural strength compared to the mix without bagasse ash. The variations of the flexural strength are shown in Fig. 3.

\subsection{Saturated water absorption}

The saturated water absorption tests for various highperformance concrete blended with bagasse ash (HPC-BA) mixes at the age of 28 days curing was $1.75,1.51,1.21,1.10$ and $1.15 \%$, respectively, as shown in Table 4, and at the age of 90 days, the water absorption values was around $1.57,1.30,1.15,1.08$ and $1.27 \%$, respectively. The addition of bagasse ash with high-performance concrete mixes on the water absorption and the variation of saturated water

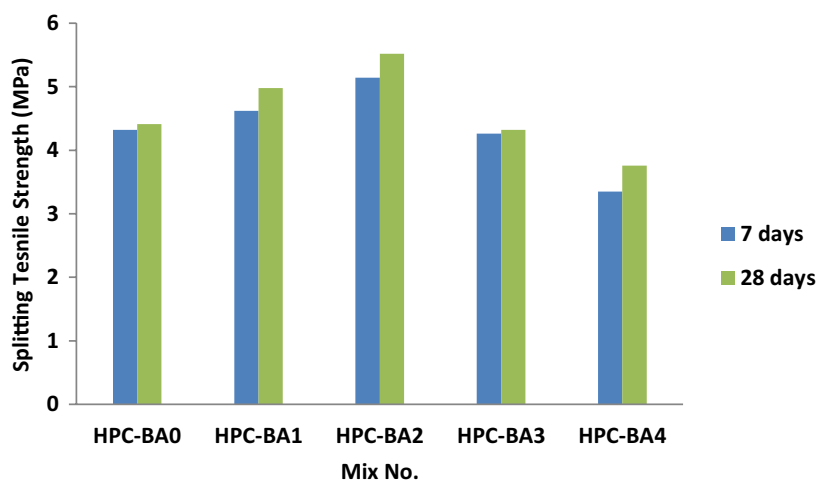

Fig. 2 Variation of splitting tensile strength

absorption with various proportions of bagasse ash are shown in Fig. 4. The optimum percentage of replacement of cement by bagasse ash was $15 \%$ for achieving the lowest values of SWA. Figure 4 shows that the bagasse ashblended high-performance concrete mixes at the age of 28 days varies from 13 to $38 \%$ decrease in water absorption compared to with that of HPC without bagasse ash. The reduction in percentage of water absorbed is due to the filler effects of small pores in concrete and pozzolanic reaction between the blended materials which strengthened the surface morphology of concrete, bringing about fine and intermittent pore structure.

\subsection{Sorptivity}

The sorptivity values measured for HPC specimens at different ages of curing are shown in Table 4. From Fig. 5, it is experiential that the sorptivity of the HPC mixes containing bagasse ash was lesser when compared with that of HPC mixes free from bagasse ash. The reduction in sorptivity varies from 14.81 to $9.25 \%$ for different bagasse ash-blended high-performance concrete. It was observed

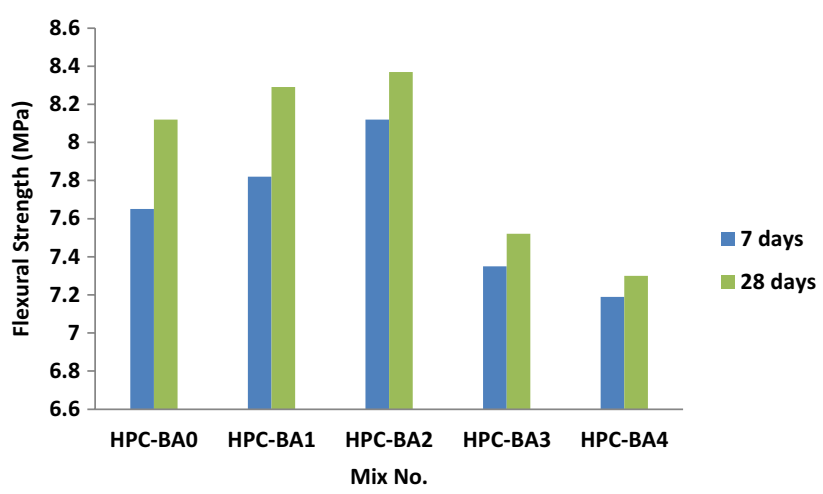

Fig. 3 Variation of flexural strength
Fig. 1 Variation of compressive strength

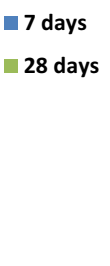

SN Applied Sciences

a SPRINGer NatURE journal 
Table 4 Durability properties of bagasse ash-blended HPC

\begin{tabular}{|c|c|c|c|c|c|c|c|c|c|c|c|c|}
\hline \multirow[t]{3}{*}{ Mix no. } & \multirow{2}{*}{\multicolumn{2}{|c|}{ SWA (\%) }} & \multirow{2}{*}{\multicolumn{2}{|c|}{ Porosity (\%) }} & \multirow{2}{*}{\multicolumn{2}{|c|}{$\begin{array}{l}\text { Sorptivity }(\mathrm{mm} / \\
\left.\min ^{0.5}\right)\end{array}$}} & \multicolumn{6}{|c|}{ Reduction compared to conventional concrete } \\
\hline & & & & & & & \multicolumn{2}{|l|}{ SWA (\%) } & \multicolumn{2}{|c|}{ Porosity (\%) } & \multicolumn{2}{|c|}{$\begin{array}{l}\text { Sorptivity }(\mathrm{mm} / \\
\left.\min ^{0.5}\right)\end{array}$} \\
\hline & 28 days & 90 days & 28 days & 90 days & 28 days & 90 days & 28 days & 90 days & 28 days & 90 days & 28 days & 90 days \\
\hline HPC-BAO & 1.75 & 1.57 & 2.70 & 2.40 & 0.0318 & 0.0304 & - & - & - & - & - & - \\
\hline HPC-BA1 & 1.51 & 1.30 & 2.30 & 2.25 & 0.0273 & 0.0257 & 13.71 & 17.19 & 14.81 & 6.25 & 14.15 & 15.46 \\
\hline HPC-BA2 & 1.21 & 1.15 & 2.20 & 2.10 & 0.0242 & 0.0234 & 30.85 & 26.75 & 18.51 & 12.50 & 23.89 & 23.02 \\
\hline HPC-BA3 & 1.10 & 1.08 & 2.35 & 2.15 & 0.0251 & 0.0245 & 37.14 & 31.21 & 12.96 & 10.41 & 21.06 & 19.40 \\
\hline HPC-BA4 & 1.15 & 1.27 & 2.45 & 2.20 & 0.0258 & 0.0247 & 34.20 & 19.10 & 9.25 & 8.33 & 18.86 & 18.75 \\
\hline
\end{tabular}

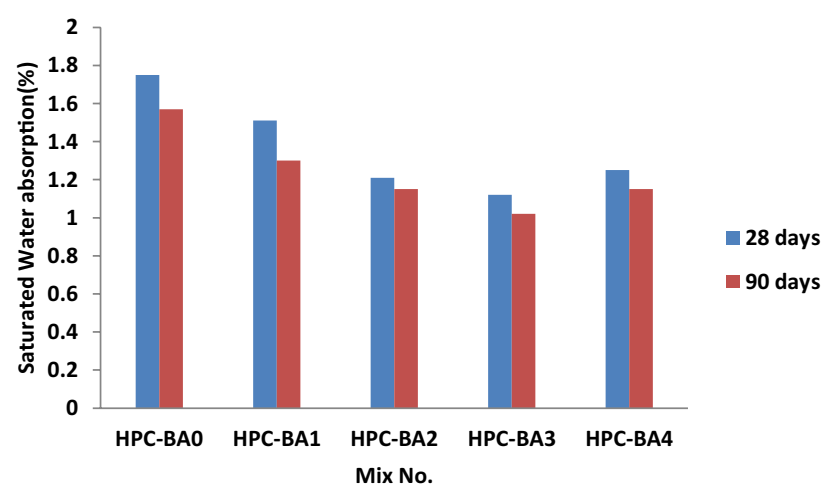

Fig. 4 Variation of saturated water absorption

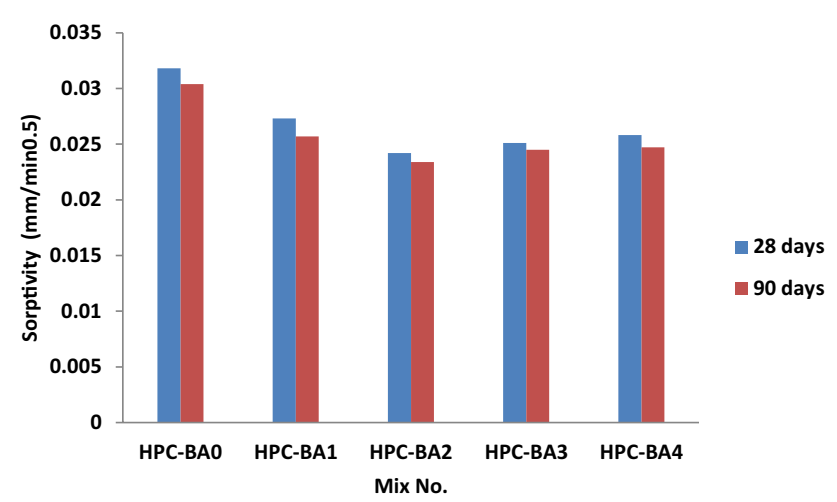

Fig. 5 Variation of sorptivity

that due to fineness of bagasse ash, water-level rise, due to which capillary action decreases in HPC [19].

The transformation of large pores into fine pores was achieved in fly ash-blended concrete due to the low permeability, which increases the pore reinforcement. Occurrence of pore reinforcement is due to the conversion of calcium hydroxide into calcium silicate hydrate gel by silica content (pozzolanic), which fills the large voids in hydrated cement and liberates some amount of calcium hydroxide. Similar pozzolanic reaction takes

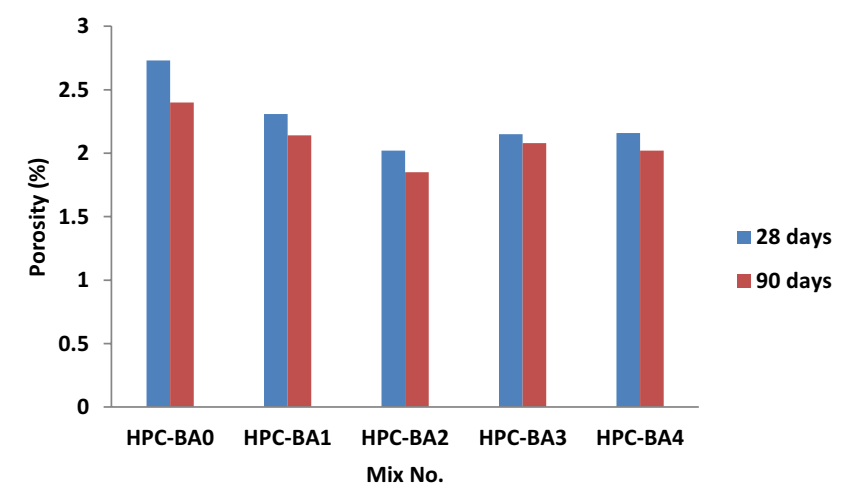

Fig. 6 Variation of porosity

place in BA-blended HPC, in which BA converts calcium hydroxide into calcium silicates. Thus, due to the effect of BA between cement paste phase and aggregate phase in transition zone, HPC gets lower permeability. Generally, transition zone is less dense in plain cement concrete than the cement paste and has minimum amount of crystal of calcium hydroxide, which gets reduced due to the addition of BA. The pores (micro and macro) present in HPC are filled by finer particles.

\subsection{Porosity}

The results of porosity study of concrete at 28 and 90 days are shown in Table 4. The porosities of concrete containing $15 \%$ and $20 \%$ of bagasse ash (HPC-BA3 and HPC-BA4) were higher than conventional concrete at the same period. It was observed that more the bagasse ash content, more the porosities of HPC. On the other hand, for the $10 \%$ of BA replacement (HPC-BA2), the fine particle size of pozzolan modified the pore structure and reduced the porosity of concrete. The variation in porosity of bagasse ash-blended high-performance concrete is shown in Fig. 6. 


\subsection{Impact test}

The impact test results for 28 days are shown in Table 5 . From Fig. 7, it is noted that the impact resistance of highperformance concrete mixes containing bagasse ash was more than that of HPC mixes without bagasse ash. Increase in the percentage of bagasse ash enhanced the impact resistance of HPC. This is because of the formation of certain quantity of constant $\mathrm{C}-\mathrm{S}-\mathrm{H}$ in high-performance concrete with bagasse ash.

\subsection{Alkalinity measurement}

The $\mathrm{pH}$ values of the aqueous solution prepared from HPC powder samples at 28 days curing are shown in Table 5. The HPC mixes containing bagasse ash showed lower value of $\mathrm{pH}$ compared to HPC mixes without bagasse ash. The variation of $\mathrm{pH}$ values is shown in Fig. 8. The concrete mixes containing bagasse ash showed lesser value of $\mathrm{pH}$ as compared to concrete mix without bagasse ash. The lower value of $\mathrm{pH}$ is due to lime consumption in pozzolanic reaction, and the free lime in concrete required to keep high $\mathrm{pH}$ in cement concrete is very low. Hence, there is no significant loss of alkalinity due to pozzolanic reaction between silica of bagasse ash and free calcium hydroxide of cement paste.

\section{Conclusions}

From the experimental work carried out, the following conclusions can be obtained.

1. The early compressive strength development may be due to the reaction of bagasse ash with $\mathrm{CaO}$, which improves the hardening process in bagasse ashblended HPC.

Table 5 Alkalinity measurement and impact strength of bagasse ash-blended HPC

\begin{tabular}{lllll}
\hline Mix no. & $\begin{array}{l}\text { pH value of samples } \\
\text { (28 days curing) }\end{array}$ & $\begin{array}{l}\text { Number } \\
\text { of blows }\end{array}$ & $\begin{array}{l}\text { Energy absorbed for } \\
\text { ultimate failure }(\mathrm{N} \mathrm{m})\end{array}$ \\
\cline { 2 - 4 } & pH meter $\begin{array}{c}\mathrm{pH} \\
\text { indicating } \\
\text { papers }\end{array}$ & \\
\hline HPC-BA0 & 13.40 & $>13$ & 180 & 3636 \\
HPC-BA1 & 13.23 & $>13$ & 210 & 4242 \\
HPC-BA2 & 13.16 & $>13$ & 224 & 4524 \\
HPC-BA3 & 13.10 & $>13$ & 231 & 4666 \\
HPC-BA4 & 13.05 & $>13$ & 238 & 4807 \\
\hline
\end{tabular}

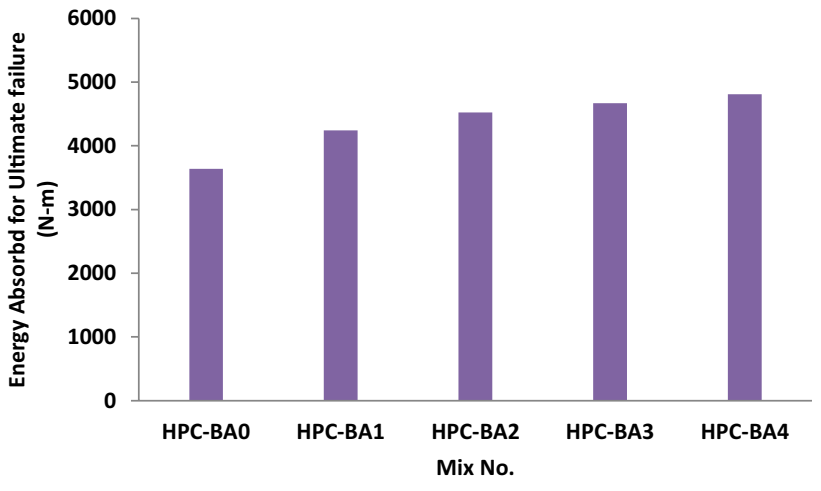

Fig. 7 Variation of impact strength

2. The splitting tensile strength increases gradually from 12.92 to $25.17 \%$ for the cement replacement of $5-10 \%$ of bagasse ash at the age of 28 days.

3. The flexural strength was increasing gradually from 2.09 to $3.08 \%$, respectively, for the bagasse ash replacement level of $5-10 \%$. Therefore, inclusion of bagasse ash improves strength properties of concrete up to $10 \%$. Bagasse ash acts as micro-filler and improves the density of cement paste. The bond between the cement paste and the aggregate particles is enhanced and improves the concrete strength.

4. Due to the reduced permeable voids after 90 days of curing, the percentage of water absorption values of bagasse ash-blended HPC mix decreased reasonably.

5. Sorptivity of bagasse ash-blended HPC at 28 and 90 days curing gradually reduced with the increase in the bagasse ash content up to $20 \%$, when compared with the control mix specimen.

6. The porosity of the HPC mixes varies from 2.20 to $2.70 \%$ at the age of 28 days. Similarly porosity varies from 2.10 to $2.40 \%$ at the age of 90 days. The porosity of the bagasse ash-blended HPC mixes was lower than the HPC mix without bagasse ash. Durability proper-

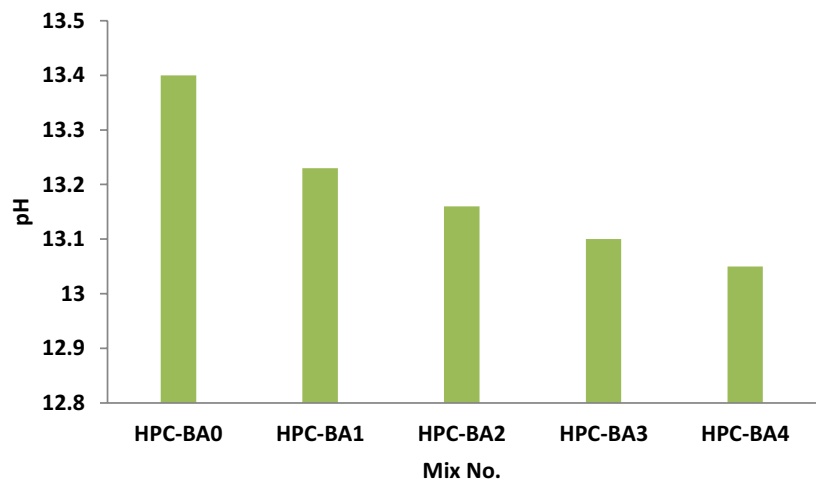

Fig. 8 Variation of alkalinity measurement 
ties of HPC mixes blended with bagasse ash show significant improvement between $10 \%$ and $15 \%$ of replacement of cement.

7. Due to the formation of constant $\mathrm{C}-\mathrm{S}-\mathrm{H}$ in HPC mixes, impact resistance of bagasse ash-blended HPC mixes showed higher values compared to that of mixes without bagasse ash.

8. The $\mathrm{pH}$ values of HPC powder sample blended with bagasse ash showed lower value of 13.05 to 13.23 compared to sample without bagasse ash, where there is no loss of alkalinity significantly. The reduction in the $\mathrm{pH}$ is due to the presence of high magnesium content, which gradually replaces calcium hydroxide in HPC.

Acknowledgements The authors wish to thank UGC, New Delhi, for their financial support under minor research Project MRP6458/16(SERO/UGC) and Dr. R. Rudramoorthy, Principal, PSG College of Technology, Coimbatore, for the facilities and support provided in carrying out this research work at Advanced Concrete Research Laboratory.

\section{Compliance with ethical standards}

Conflict of interest The authors declare that they have no conflict of interest.

Ethical approval This article does not contain any studies with human participants or animals performed by any of the authors.

\section{References}

1. Bentur A (2002) Cementituous materials-nine millennia and a new century: past, present and future. ASCE J Mater Civ Eng 14(1):1-22

2. Caldarone MA, Gruber KA, Burg RG (1994) High reactivity metakaloin: a new generation mineral admixture. Concr Int 16(11):37-40

3. Ismat A (2004) Biomass: an ideal fuel for sugar mills for steam/ power generation, 197th edn. Fuel Research Centre, PCSIR, Karachi
4. Wild S, Khatib JM, Jones A (1996) Relative strength pozzolanic activity and cement hydration in superplasticised metakolin concrete. Cem Concr Res 26:1537-1544

5. Mehta PK (1977) Properties of blended cement made from rice husk ash. ACI Mater J 74(9):440-442

6. Biricik H, Akoz F, Berktay I, Tulgar AN (1999) Study of pozzolanic properties of wheat straw ash. Cem Concr Res 29:637-643

7. Boateng AA, Skeete DA (1990) Incineration of rice hull for use as a cementitious materials: the guyana experience. Cem Concr Res 20(5):795-802

8. Balasubramanian SV, Ratnavelu KN (2001) Budget performance of sugar industry. In: Proceeding of South India sugar mills association

9. Hernandez JM, Rodriguez BS, Middendorf B (2001) Pozzolanic properties of residues of sugar industries (second part). Mater Constr 51(261):67-72

10. Amin N, Shah MT, Ali K (2009) Raw mix designing and clinkerization high strength Portland cement from the raw material of Darkhula Nizampur. Mag Concr Res 61(10):779-785

11. IS 383 (2016) Coarse and the fine aggregate for concrete-specification. Bureau of Indian Standards, New Delhi

12. Aitcin PC (1998) High performance concrete. CRC Press, Boca Raton

13. IS 516 (2004) Method of tests for strength of concrete. Bureau of Indian Standards, New Delhi

14. IS 5816 (2004) Splitting tensile strength of concrete-method of test. Bureau of Indian Standards, New Delhi

15. ASTM C 642 (1990) Standard test method for specific gravity, absorption, and voids in Hardened concrete. American Society for Testing Materials Standard, Philadelphia

16. Kim Y-Y, Lee K-M, Bang J-W, Kwon S-J (2014) Effect of W/C ratio on durability and porosity in cement mortar with constant cement amount. Adv Mater Sci Eng 24:273460

17. Hall C (1989) Water sorptivity mortars and concretes: a review. Mag Concr Res 41(147):51-61

18. Ganesan K, Rajagopal K, Thangavel K (2007) Evaluation of bagasse ash as supplementary cementitious material. Cem Concr Res 29:515-524

19. Cordeiro GC, Tavares LM, Toledo Filho RD (2016) Improved Pozzolanic activity of sugarcane baggase ash by selective grinding and classification. Cem Concr Res 89:269-275

Publisher's Note Springer Nature remains neutral with regard to jurisdictional claims in published maps and institutional affiliations. 